\title{
EHST 2020
}

PROCEEDINGS OF THE 4TH

INTERNATIONAL CONFERENCE

ON ENERGY HARVESTING, STORAGE, AND TRANSFER (EHST'20)

November 15, 2020 - November 17, 2020 | Niagara Falls, Canada-| Virtual Conference

(๖ COPYRIGHT 2020, INTERNATIONAL ASET INC. - ALL RIGHTS RESERVED.

ISBN: 978-1-927877-81-4 | ISSN: 2561-1097 


\section{TABLE OF CONTENTS}

Welcome Message from the Conference Chair............................... 3

About EHST'20........................................................... 4

Scientific Committee..................................................... 5

Keynote Speakers...................................................... 6

List of Papers ......................................................... 8

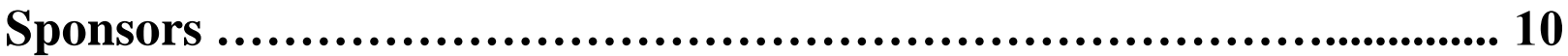

Journal Special Issue........................................................... 11

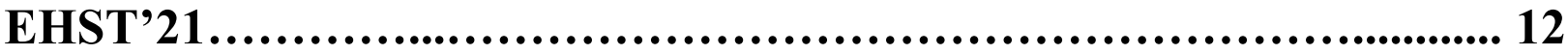

Ethics \& Malpractice ...................................................... 13

Contact Us ................................................................. 18 


\section{WELCOME MESSAGE FROM THE CONFERENCE CHAIR}

On behalf of the International Academy of Science, Engineering and Technology (International ASET Inc.), the organizing committee would like to welcome you to the $4^{\text {th }}$ International Conference of Energy Harvesting, Storage, and Transfer (EHST'20).

EHST'20 is aimed to become one of the leading international annual conferences in the fields related to energy harvesting, storage, and transfer. This conference will provide excellent opportunities to the scientists, researchers, industrial engineers, and university students to present their research achievements and to develop new collaborations and partnerships with experts in the field.

In the first meeting of this conference, three keynote speakers will share his expertise with the aim of exposing participants to a wide spectrum of applications, and to foster crosspollination of ideas and develop new research interests. In addition, approximately 20 papers will be presented from professors, students, and researchers across the world.

We thank you for your participation and contribution to the $4^{\text {th }}$ International Conference of Energy Harvesting, Storage, and Transfer (EHST'20). We wish you a very successful and enjoyable experience.

\section{Dr. Boguslaw Kruczek}

Conference Chair and Proceedings Editor

FFHMT'20

\section{Dr. Xianshe Feng}

Conference Co-Chair and Proceedings Editor

FFHMT'20

Dr. Wael H. Ahmed

Technical Program Chair

FFHMT'20 


\section{ABOUT EHST'20}

The $4^{\text {th }}$ International Conference of Energy Harvesting, Storage, and Transfer (EHST'20) aims to become the leading annual conference in fields related to energy harvesting, storage, and transfer. The goal of EHST'20 is to gather scholars from all over the world to present advances in the fields related to energy harvesting, storage, and transfer and to foster an environment conducive to exchanging ideas and information. This conference will also provide an ideal environment to develop new collaborations and meet experts on the fundamentals, applications, and products of the mentioned fields.

EHST is a series of international conferences held yearly. These conferences focus on all aspects of Energy Harvesting, Storage, and Transfer. After successfully holding EHST'19 in Canada, EHST'20 is hosted in Canada as well this year.

EHST is an acronym for Energy, Harvesting, Storage, and Transfer.

The proceedings is published in Niagara Falls, Canada.

All papers were peer-reviewed

The congress proceedings is published under an ISSN and ISBN number Each paper is assigned a unique DOI number by $\underline{\text { Crossref }}$

The conference proceedings is indexed by Google Scholar

The proceedings is permanently archived in Portico (one of the largest community-supported digital archives in the world)

\section{Google Scholar}

Return to Top

\section{Crossref}

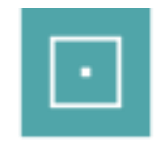

PORTICO 


\section{SCIENTIFIC COMMITTEE}

We would like to thank the following for accepting to act as a member of the Scientific Committee for the EHST'20 Conference:

Scientific Committee Chairs

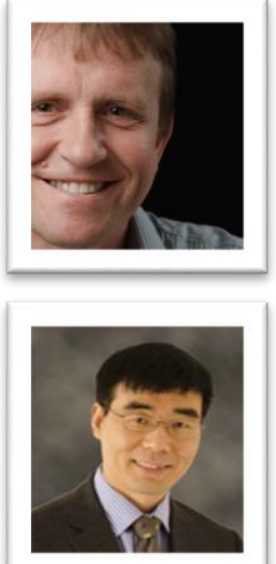

Dr. Boguslaw Kruczek

University of Ottawa, Canada

Conference Chair

\section{Scientific Committee Members}

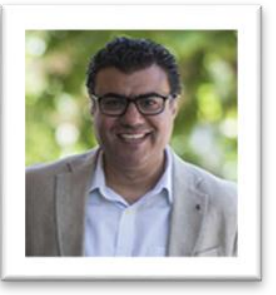

Dr. Wael H. Ahmed University of Guelp, Canada

Technical Program Chair

Dr. Yang-Tse Cheng, University of Kentucky, USA

Dr. Ming-Jyh Chern, National Taiwan University of Science and Technology, Taiwan

Dr. Eduard Doujak, Vienna University of Technology, Austria

Dr. Jean Duquette, Carleton University, Canada

Dr. Ursula Eicker, Concordia University, Canada

Dr. Kamel Hooman, The University of Queensland, Australia

Dr. Nattaphorn Kaewprathum, Dairy Farming Promotion Organization Of Thailand, Thailand

Dr. Sumathy Krishnan, University of North Dakota, USA

Dr. Sylvie Lorente, INSA Toulouse, France

Dr. Lin Liu, University of Kansas, USA

Dr. Robert Morgan, University of Brighton, UK

Dr. Ngalula S. Mubenga, University of Toledo, USA

Dr. Laurent Pilon, University of California, LA, USA

Dr. Krishnan Raja, University of Idaho, USA

Dr. Murari Roy, Lakehead University, Canada

Dr. Carey J. Simonson, University of Saskatchewan, Canada

Dr. Ali Tarokh, Lakehead University, Canada

Dr. Liang Yu, Beijing Institute of Technology, China

Dr. Hadis Zarrin, Ryerson University, Canada

Dr. Igor Zhitomirsky, McMaster University, Canada 


\section{KEYNOTE SPEAKERS}

The keynote information for the 4th International Conference of Energy Harvesting, Storage, and Transfer (EHST'20) is as follows:

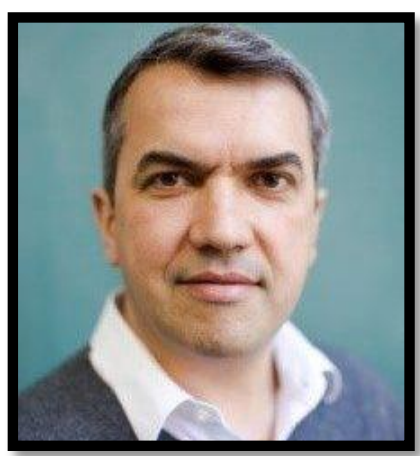

\section{Dr. Laurent Pilon}

\section{University of California, USA}




\section{EHST'20 KEYNOTE LECTURE}

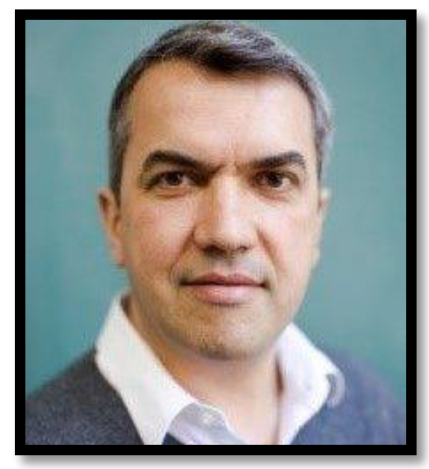

Titles: Innovative Materials for Energy Efficient Buildings Dr. Laurent Pilon, University of California, LA, USA

\section{View Abstract}

\section{Return to Top}

Laurent Pilon received his B.S. and M.S. in Applied Physics from the Grenoble Institute of Technology, France and his PhD in Mechanical Engineering from Purdue University, USA in 2002. He then joined the Mechanical and Aerospace Engineering Department at the University of California, Los Angeles (UCLA) where he is now Professor. His research group is engaged in a wide range of interdisciplinary research projects at the intersection of interfacial and transport phenomena, material science, and biology for the development of sustainable energy conversion, storage, and efficiency technologies. He has authors more than 160 archival journal publications. He is also the recipient of several awards including the CAREER Award from the National Science Foundation and the Bergles-Rohsenow Young Investigator Award in Heat Transfer from the American Society of Mechanical Engineers (ASME). He is a Fellow of ASME and a member of the Scientific Council of the International Center for Heat and Mass Transfer (ICHMT). 


\section{LIST OF PAPERS}

The following papers were presented at the 7th International Conference on Control, Dynamic Systems, and Robotics (CDSR'20).

\section{Energy Harvesting, Storage, and Management}

Title: Numerical Modeling of Surface Roughness Effects on the Natural Frequency of a Silicon Cantilever

Authors: Jean Marriz Manzano, Magdaleno Vasquez, Marc Rosales, Maria Theresa De Leon

\section{View Paper}

Title: Experimental Investigation of Energy Consumption of $A$ Commercial Walkin Freezer

Authors: Mohamed Metwalli, Minhajul Haque Minar, Mostafa H. Sharqawy

\section{View Paper}

Title: A Smart Billing System for Enhancement of Renewable Energy to Non-Electrified Communities in Nigeria

Authors: Olufemi Abraham

\section{View Paper}

Title: Optimal Planning of Energy Storage System in a PV Integrated SemiUrban Microgrid Pilot Authors: Olufemi Abraham

\section{View Paper}




\section{LIST OF PAPERS}

\section{Sustainable Energy}

Title: Vibration Energy Harvesting Dampers for Massive Large-Scale Objects

Authors: George Nerubenko, David Flowers, Ivan Biliuk

\section{View Paper}

Title: Simulation of Phase Change Material Melting Process in Presence of Nanofluid as an Auxiliary Fluid

Authors: Alireza Khademi, Arash Mousemi, Ali Parcheforosh, Mohammad Behshad Shafii, Giancarlo Sorrentino

\section{View Paper}

Title: Ecological Potential of Osmotic Power Generation by Pressure Retarded Osmosis in Ontario, Canada

Authors: Bassel A. Abdelkader, Mostafa H. Sharqawy

\section{View Paper}




\section{SPONSORS}

International ASET Inc. would like to thank the following sponsors for their support of EHST'20:
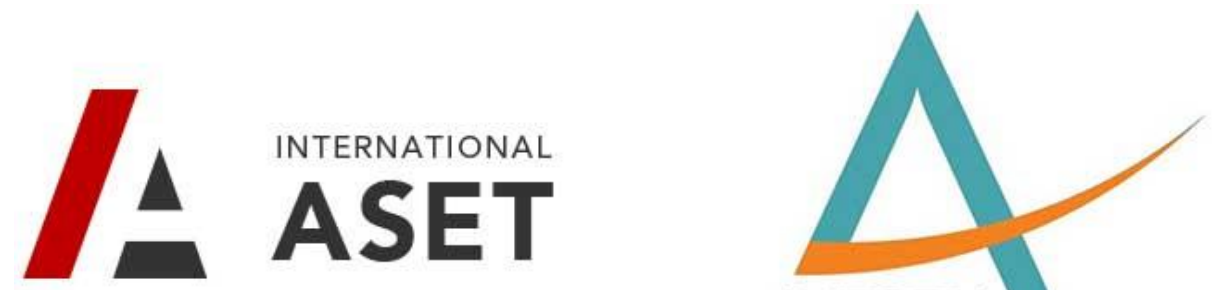

AVESTIA

\section{WHERE (2) SUBMIT}




\section{JOURNAL SPECIAL ISSUES}

Selected articles from the coference will be published in the Journal of Fluid Flow, Heat and Mass Transfer (JFFHMT) after a secondary review process.

The publication fee will be waived for papers that win the best paper award. Other attendees will receive a $25 \%$ discount towards the publication fee of the journal.

This journal has adopted to the open-access model, meaning all free access to the journal's articles and content with no need for subscription. This ensures larger audience and therefore higher citations.

Users are allowed to read, download, copy, distribute, print, search, or link to the full texts of the articles in this journal without asking prior permission from the publisher or the author. This is in accordance with the BOAI defi nition of open access.

All published papers of JFFHMT will be submitted to Google Scholar, Microsoft Academic Search, Open J-Gate, Mendeley, Index Copernicus International, Academic Index, Mendeley, Primo Central, and Genomics JournalSeek for possible indexing. Additionally, they will be permanently archived in Portico (one of the largest community-supported digital archives in the world) and will be assigned unique DOIs. 


\section{EHST'21}

The 5th International Conference on Energy Harvesting, Storage, and Transfer (EHST'21) will be held in May 21 - 23, 2021 in Niagara Falls, Canada.

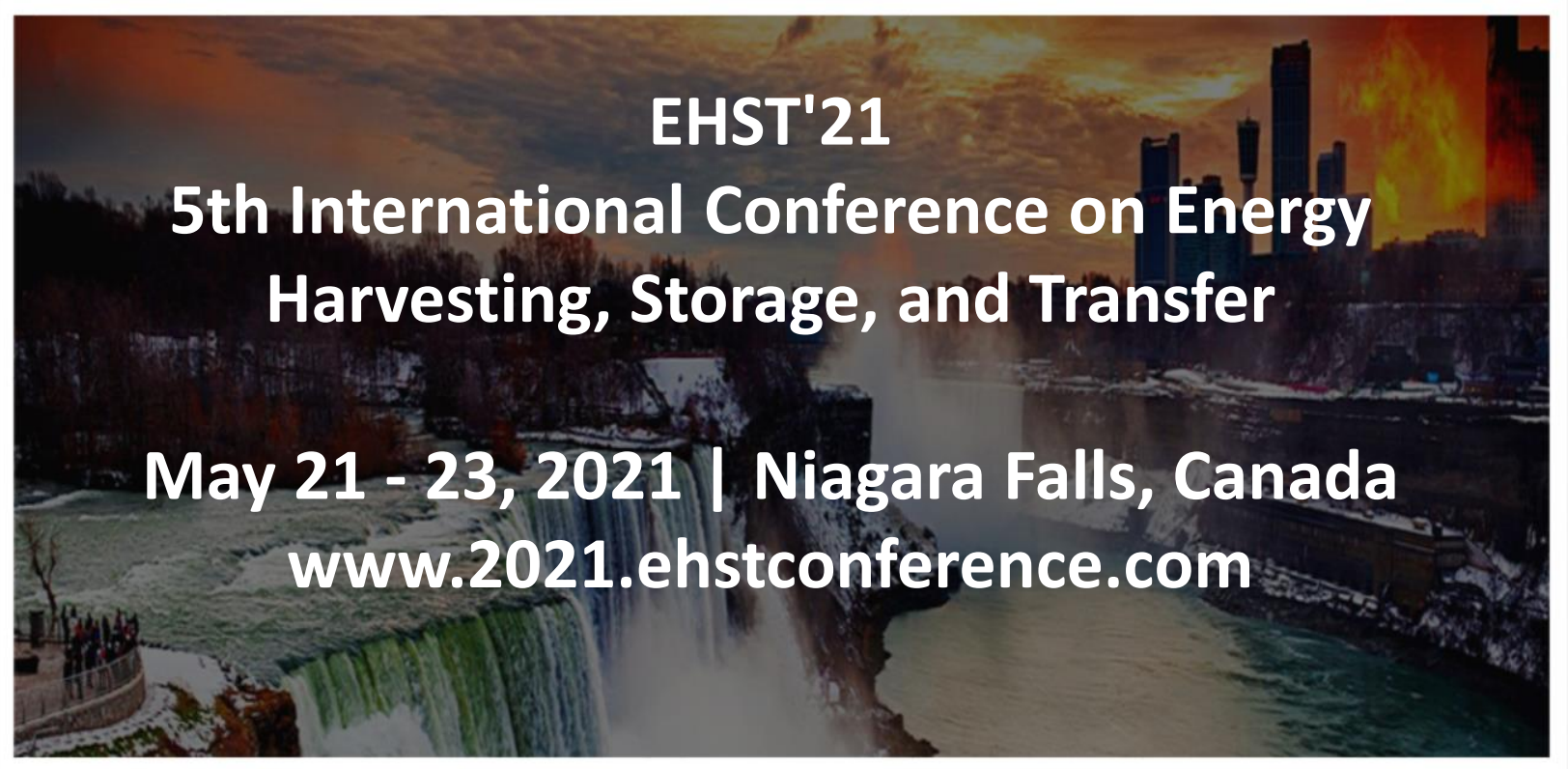

For inquiries and to obtain further information on the congress, please visit the website or call us at:

+1-613-834-9999

\section{Return to Top}




\section{ETHICS \& MALPRACTICE}

\section{Publication Ethics and Publication Malpractice Statement}

The following statement is mainly based on the Code of Conduct and BestPractice Guidelines for Journal Editors (Committee on Publication Ethics, 2011).

\section{Scientific Committee}

\section{Scientific Committee}

Scientific committees consisting of experts in the fields are established. The committees oversee the peer-review and publication process. To see the scientific committee members, please follow the link below.

\section{Scientific Committee}

\section{Equality and Decisions}

One or more reviewer, scientific committee member, or chair, (internal or external), are responsible for evaluating the relevance of the submitted manuscripts to the proceedings, technical and scientific merit, originally, and impact. These evaluations are to be carried out regardless of ethnicity, religion, gender, sexual orientation, political beliefs, and institutions. Successive to peer-review, the Chair has full authority and is solely responsible for the published content and the process thereof.

\section{Confidentiality}

Scientific committee member(s) and publishing staff may not disclose manuscripts or their content, directly or indirectly, to anyone other than individuals invited to review the manuscript (whether they accept or not), other reviewers of the same publications, and publishing staff.

\section{Conflicts of Interest}

Scientific committee member(s) and publishing staff may not utilize the contents of submitted manuscripts whether accepted or rejected, directly or indirectly for their own research purposes without prior written consent by the authors. 


\section{ETHICS \& MALPRACTICE}

\section{Reviewers}

\section{Contribution to Decisions}

In order for final decisions to be made regarding acceptance or rejection of papers, we rely on peer-review. Peer-review is the process of experts in the field reading, understanding, and objectively commenting on submitted papers. Through peer-review, scholars give back to the academic and scientific community by helping the chair(s) make decisions regarding manuscripts.

\section{Promptness}

Reviewers should promptly notify the chair(s) if they are unable or unqualified to carry out their reviewing duties. Reviewers should do their best to provide the reviews to the chair(s) as promptly as possible, and within the designated time-frame.

\section{Confidentiality}

Reviewers must not share the contents of the manuscripts they receive for review, regardless of their decision to review or contents of the review, directly or indirectly, with anyone other than the person who has assigned the review.

\section{Fairness}

Reviewers should review manuscripts fairly and objectively, with supporting evidence or arguments, regardless of personal feelings or biases.

\section{Thoroughness}

Reviewers should thoroughly read, understand, and provide constructive feedback with the aim of improving the manuscript. Reviewers should aim to identify and report technical issues, irregularities, mistakes, missing citations, and similarity to other published work.

\section{Conflicts of Interest}

Invited reviewers should immediately inform the chair(s) in case of a conflict of interest based on competitive, collaborative, personal, family, and other relationships with the authors or people involved in the work. 


\section{ETHICS \& MALPRACTICE}

\section{Authors}

\section{Authorship}

Only persons who have significantly contributed to the work and the manuscript can be named authors on a paper. These contributions include the idea/concept, design, experiments, evaluation, analysis, drafting or revision of the manuscript, and others. Authors must all have agreed to be named as such and for the manuscript to be submitted. Anyone who has contributed based on the above, but the level of contribution is not significant, may appear in the acknowledgement section of the manuscript.

\section{Accuracy, Originality, and Plagiarism}

Authors should describe their work and the results of their work accurately and in full. The level of provided accuracy and detail should be such that a reader can replicate the work independently. Inaccurate, incomplete, fraudulent, and misleading statements are considered unacceptable and unethical. Direct or indirect use of other people's work is not allowed, unless properly cited. Previous works that have influenced the current work should also be cited. Presenting someone else's work as one's own is strictly prohibited and is considered plagiarism.

\section{Data and Material}

Authors are encouraged to share their data, software, or other sharable material online, provided copyright and ownership laws surrounding that particular project permit. Authors may also be asked to share such material with the chair(s), and/or reviewers, and must be willing to do so if asked.

\section{Dual Submissions}

Submitting a manuscript to more than one venue (conference, journal, etc) simultaneously is not allowed. Presenting previously published work to be considered as a new submission, without a significant new interpretation or analysis, is prohibited. 


\section{ETHICS \& MALPRACTICE}

\section{Conflicts of Interest}

Authors must notify the chair(s) at the time of submission, if any factor outside the scope of the research has influenced any step of the work and manuscript writing. Examples of such factors include but are not limited to funding, grants, advisory and consultancy, stock ownership, current or past employment, and memberships, among others. All funding sources should be disclosed in the manuscript.

\section{Animal and Human Subjects}

Works involving human and/or animal subjects must ensure that the work has abided by institutional guidelines, and pre-approved by required bodies. Moreover, consent must be acquired from participants, and privacy of subjects must be ensured. All of the above must be specified with clear statements in the manuscript.

\section{Hazardous Material}

It should clearly be identified in the manuscripts if the works have involved hazardous chemicals and material, or devices that can be harmful.

\section{Reporting of Mistakes, Errata, and Retractions}

If an author identifies a major error in a published paper, he/she must immediately identify the publisher. Regardless of whether a significant error is reported by the authors of the work or other readers, authors are obligated to take the necessary steps to correct the issue. It is decided on a case-by-case basis whether an erratum will be submitted to notify future readers of the error and correction, or whether the paper will be retracted. Unethical/plagiarism issues mostly result in a retraction, while unintended mistakes will mostly result in the publication of an erratum. 


\section{ETHICS \& MALPRACTICE}

\section{Publisher}

\section{Errata and Retractions}

The publisher takes the necessary steps to prevent mistakes, academic and scientific misconduct, and unethical behavior, both intended and unintended. When mistakes are reported, the publisher works with chair(s) and authors to publish an erratum clarifying the issue. In cases where the mistakes are severe and significant, the paper might be retracted. If unethical behavior, plagiarism, academic and scientific misconduct, or other such activities are proven to have taken place by an author or authors, the publisher will retract the paper.

\section{Content and Archiving}

The publisher preserves and stores all content digitally on their own servers, as well as through partnering with Portico (Digital Preservation and Electronic Archiving Service).

\section{Copyright and Access}

The proceedings and related papers are all based on the open-access model, which means interested individuals and institutions can access the material for free.

Users are allowed to read, download, copy, distribute, print, search, or link to the full texts of the articles in this proceedings without asking prior permission from the publisher or the author. This is in accordance with the BOAl definition of open access.

\section{Ownership and Management}

This conference-proceedings is managed and operated by the International ASET (International Academy of Science, Engineering, and Technology) and Avestia Publishing (the publishing arm of ASET).

\section{Schedule}

This conference proceeding accompanies the conference, meaning a new proceedings will be published every year for the corresponding annual conference of this series. 


\section{CONTACT US}

For inquiries and to obtain further information on the conferences, please visit our website or call us at: +1-613-834-9999

\section{Return to Top}

